\title{
Proses Quenching and Partitioning Terhadap Sifat Mekanik Baja Karbon Medium
}

\author{
Ali Alhamidi*, Salsabila Nur Fitriani, Yeni Muriani Zulaida, Tri Partuti, Indah Uswatun Hasanah \\ Jurusan Teknik Metalurgi, Fakultas Teknik, Universitas Sultan Ageng Tirtayasa \\ Jl. Jend. Sudirman km. 03 Cilegon, Banten \\ *E-mail: alhamidi@untirta.ac.id
}

\begin{abstract}
Abstrak
Baja WRM 1045 adalah baja karbon sedang yang menawarkan sifat mekanik yang baik dan diterapkan untuk industri otomotif seperti poros engkol. Menurut JIS G4051 bahwa sifat mekanik untuk poros engkol diharapkan memiliki kekuatan luluh $\sim 490 \mathrm{MPa}$, kekuatan tarik minimum, dan perpanjangan $686 \mathrm{MPa}$ dan 17\%. Dalam penelitian ini, baja WRM 1045 diproses melalui proses Quenching and Partitioning (Q\&P). Itu dilakukan dengan variasi waktu penahanan 30 dan 60 menit selama austenitisasi dan suhu partisi 225, 250, 275, dan $300{ }^{\circ} \mathrm{C}$. Pengujian tarik, uji kekerasan dan metalografi dilakukan untuk menentukan sifat mekanik dan struktur mikro baja WRM KS1045. Hasil penelitian menunjukkan bahwa sifat mekanik menurun dengan meningkatnya suhu partisi dan waktu penahanan austenit. Semakin tinggi sifat mekanik dicapai setelah waktu tahan austenit 60 menit dan suhu partisi $275^{\circ} \mathrm{C}$ dengan kekuatan luluh 520,70 MPa, kekuatan tarik 784,63 MPa, perpanjangan 15\%, dan kekerasan 93,33 HRB. Analisis struktur mikro optik terdiri dari martensit dan retensi austenit setelah proses Q\&P.
\end{abstract}

Diterima: 31-05-2020; Direvisi: 31-08-2020; Dipublikasi: 01-09-2020

Kata kunci: Elongasi; Kekuatan; Martensit; Quenching and Partitioning; Retained Austenit

\begin{abstract}
WRM 1045 steel is medium carbon steel which is offered good mechanical properties and applied for automotive industries such as the crankshaft. According to the JIS G4051 that the mechanical properties for crankshaft is expected to have yield strength of $\sim 490 \mathrm{MPa}$, Minimum tensile strength, and elongation are $686 \mathrm{MPa}$ and $17 \%$. In this study, the WRM 1045 steel was processed through Quenching and Partitioning (Q\&P) process. It was carried out with variations of holding time 30 and 60 minutes during austenitizing and partitioning temperatures of 225 , 250, 275, and $300{ }^{\circ} \mathrm{C}$. Tensile testing, hardness test and metallography conducted to determine the mechanical properties and the microstructure of WRM KS1045 steel. The results show that the mechanical properties decrease with increasing partitioning temperature and austenite holding time. The higher of mechanical properties were attained after austenite holding time of 60 minutes and partitioning temperature of $275{ }^{\circ} \mathrm{C}$ with the yield strength of $520.70 \mathrm{MPa}$, the tensile strength of $784.63 \mathrm{MPa}$, elongation of $15 \%$, and hardness of 93.33 HRB. Optical microstructure analysis consists of martensite and retained austenite after the Q\&P process.
\end{abstract}

Keywords: (Elongation; Strengthening; Martensite; Quenching \& Partitioning; Retained Austenite)

\section{Pendahuluan}

Salah satu penggunaan baja pada industri otomotif yaitu baja WRM 1045. Aplikasi dari baja WRM 1045 salah satunya adalah Crankshaft [1-2]. Crankshaft termasuk dalam klasifikasi baja karbon medium yang mengacu pada standar JIS G4051 S45C. Crankshaft merupakan komponen dalam mesin motor yang berfungsi sebagai pusat poros setiap gerakan piston sehingga komponen tersebut membutuhkan sifat mekanik seperti kekuatan dan kekerasan namun cukup ulet [1]. Pada aplikasinya, crankshaft sering mengalami retak (crack) pada bagian crank pin akibat adanya gaya tarik antara crankshaft dengan batang piston dan kekuatan serta elongasi yang rendah. Salah satu cara untuk memperbaiki sifat mekanik baja WRM 1045 ini biasanya dengan cara Quenching-Tempering (Q\&T). Namun hasil dari proses Q\&T dapat menurunkan kekuatan dan kekerasan baja setelah proses quenching. Metode perlakuan panas lain yang dapat digunakan untuk meningkatkan kekuatan dan kekerasan baja tanpa menurunkan elongasinya adalah Quenching and Partitioning (Q\&P).

Metode Q\&P merupakan kombinasi proses perlakuan panas baja, quenching, dan partitioning. Metode ini dilakukan dengan cara memanaskan baja sampai dengan temperatur austenisasi dan didinginkan secara cepat namun tidak sampai dengan temperatur ruang. Proses pendinginan cepat dilakukan diantara temperatur martensite start $\left(\mathrm{M}_{\mathrm{s}}\right)$ dan martensite 
finish $\left(\mathrm{M}_{\mathrm{f}}\right)$. Kemudian dilakukan proses partisi dengan memanaskan baja kembali pada temperatur tidak lebih dari temperatur $\mathrm{M}_{\mathrm{s}}$. Sehingga struktur mikro akhir yang dihasilkan berupa martensit dan sisa austenit (retained austenite, $R A$ ). Tujuan dari proses partitioning ini adalah untuk memberikan kesempatan karbon pada martensit supaya dapat berdifusi menuju RA, sehingga RA lebih stabil ketika didinginkan sampai temperatur ruang. Dengan meningkatnya jumlah martensit dan karbon pada RA dapat meningkatkan kekuatan dan kekerasan baja tanpa menurunkan elongasinya [5].

Beberapa peneliti mencoba mengembangkan metode Q\&P ini, seperti metode Two-Step Q\&P pada baja karbon rendah dengan variasi temperatur pendinginan, temperatur dan waktu partisi [4]. Metode One-Step $Q \& P$ dilakukan pada baja karbon medium paduan rendah dengan variasi waktu partitioning [7]. Kemudian metode Two-Step $Q \& P$ yang diaplikasikan pada baja Medium Mangan dengan variasi temperatur pendinginan [8-9]. Metode One-Step $Q \& P$ pada baja paduan rendah dengan variasi waktu partisi [10]. Kekurangan dari penelitian yang sudah pernah dilakukan oleh para peneliti juga belum mampu mengontrol retained austenite yang terbentuk. Adapun penelitian metode Q\&P yang telah menghasilkan elongasi 19\% harus dilakukan dengan penambahan unsur paduan berupa Chromium (Cr). Selama ini penelitian metode Q\&P yang telah dilakukan hanya fokus pada pengaruh temperatur quenching, temperatur partitioning, dan waktu partitioning. Sedangkan struktur mikro akhir yang dihasilkan pada metode Q\&P ternyata dipengaruhi juga oleh struktur utama baja ketika dilakukan proses austenisasi [11].

Pada penelitian ini, proses partitioning dilakukan dengan menggunakan furnace dan metode Q\&P yang digunakan adalah Two-Step Q\&P di bawah temperatur Martensite Start $\left(M s=332,5^{\circ} \mathrm{C}\right)$ dengan variasi waktu tahan saat proses austenisasi ( $\mathrm{t}_{\gamma}=30,60 \mathrm{menit}$ ) pada temperatur $900^{\circ} \mathrm{C}$ dan temperatur partitioning $225^{\circ} \mathrm{C}, 250^{\circ} \mathrm{C}, 275^{\circ} \mathrm{C}, 300^{\circ} \mathrm{C}$ selama 15 menit. Ketika baja dilakukan proses quenching, maka lamanya waktu tahan austenisasi akan berpengaruh pada ukuran butir yang terbentuk dan jumlah RA yang dihasilkan. Semakin lama waktu tahan proses austenisasi, akan menyebabkan ukuran butir menjadi besar. Sehingga dapat memperlambat terbentuknya martensit ketika proses initial quenching dan meningkatkan terbentuknya RA [12]. Kemudian pengaruh temperatur partitioning juga sangat mempengaruhi bentuk martensit akhir dan jumlah retained austenite. Semakin tinggi temperatur partitioning, maka semakin banyak karbon yang berpindah dari martensit menuju retained austenite [13]. Pemilihan temperatur partitioning di bawah temperatur Martensite Start (Ms) bertujuan supaya tidak terbentuk fasa bainit yang dapat mengurangi karbon pada RA [14]. Pada penelitian ini, diharapkan baja yang telah dilakukan proses Q\&P dapat meningkat sifat mekaniknya seperti kekuatan, kekerasan, dan elongasi baja WRM 1045.

\section{Material dan metodologi}

\subsection{Material}

Baja yang digunakan pada penelitian ini adalah baja WRM KS1045 (0,443\%C-0,18\%Si-0,655\%Mn-0,014\%P$0,007 \% \mathrm{~S}-0,013 \% \mathrm{Cr}-0,009 \% \mathrm{Ni}-0,014 \% \mathrm{Cu}$ ) berukuran panjang $350 \mathrm{~mm}$ dan diameter $5,5 \mathrm{~mm}$ yang dapat dilihat pada Gambar 1.

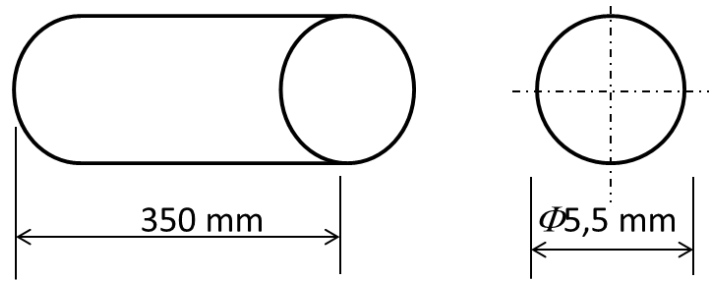

Gambar 1. Dimensi Spesimen Uji Tarik 
Ali Alhamidi, dkk./Jurnal Rekayasa Mesin p-ISSN: 1411-6863, e-ISSN: 2540-7678

Vol.15|No.2|118-125|Agustus|2020

\subsection{Proses Q\&P dan Pengujian}

Sampel dilakukan proses austenisasi pada temperatur $900^{\circ} \mathrm{C}$ dengan waktu tahan 30 dan 60 menit di dalam Muffle Furnace. Kemudian sampel dilakukan proses initial quenching dengan media air sampai temperatur quenching $200^{\circ} \mathrm{C}$, lalu dilakukan proses partitioning pada temperatur $225,250,275$, dan $300^{\circ} \mathrm{C}$ selama 15 menit. Selanjutnya sampel dilakukan proses final quenching sampai dengan temperatur kamar. Berikut ini adalah skema proses Q\&P yang dapat dilihat pada Gambar 2.

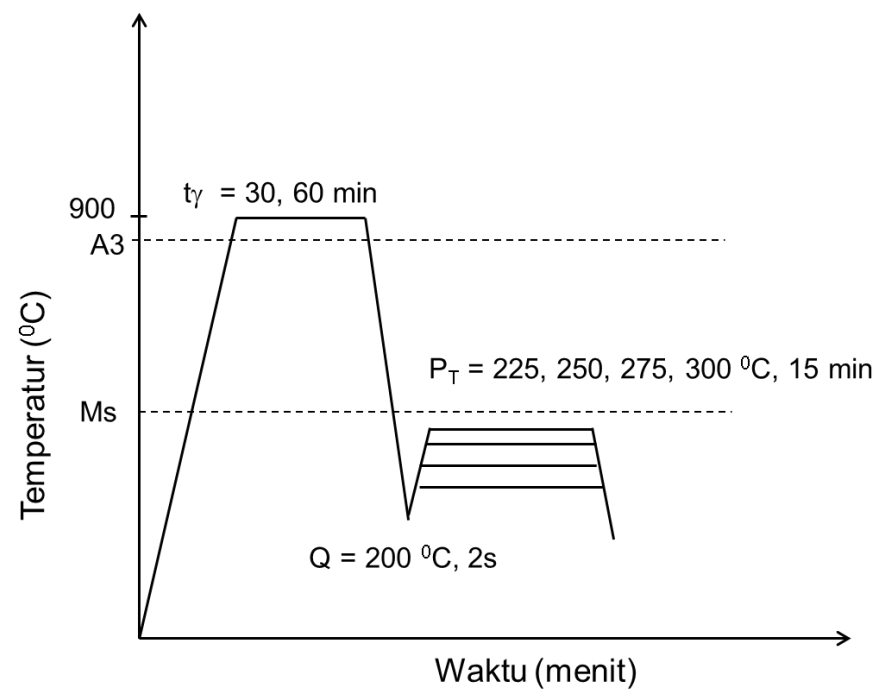

Gambar 2. Skema Proses Q\&P

Sampel yang telah dilakukan proses Q\&P, kemudian dilakukan pengujian tarik dengan standar JIS Z2241 tahun 2011, pengujian kekerasan dengan metode Rockwell, dan pengamatan metalografi dengan mikroskop optik.

\section{Hasil dan pembahasan}

Karakterisasi awal baja WRM 1045 dilakukan untuk mengetahui sifat mekanik dan struktur mikro dengan melakukan pengujian tarik, pengujian kekerasan, dan pengamatan metalografi secara kualitatif serta kuantitatif sebelum dilakukan proses (Q\&P). Berikut ini Tabel 1 merupakan sifat mekanik baja WRM 1045 berdasarkan standar JIS G4051 S45C dan hasil pengujian sebelum dilakukan proses Q\&P.

Tabel 1. Sifat Mekanik Baja WRM 1045

\begin{tabular}{ccc}
\hline Sifat Mekanik & Standar JIS G4051 S45C & Hasil Pengujian \\
\hline Kuat Luluh (MPa) & $>490$ & 408,48 \\
Kuat Tarik (MPa) & $>686$ & 728,53 \\
Elongasi (\%) & $>17$ & 12,15 \\
Kekerasan (HRB) & $>93$ & 89,67 \\
\hline
\end{tabular}

Berikut ini merupakan data hasil pengujian tarik dan kekerasan yang dapat dilihat pada Tabel 2 dan grafik pengaruh temperatur Partitioning dan waktu tahan austenisasi terhadap kekuatan luluh, kekuatan tarik, elongasi, dan kekerasan. 
Ali Alhamidi, dkk./Jurnal Rekayasa Mesin

p-ISSN: 1411-6863, e-ISSN: 2540-7678

Vol.15|No.2|118-125|Agustus|2020

Tabel 2. Hasil Pengujian Tarik dan Kekerasan

\begin{tabular}{|c|c|c|c|c|}
\hline Sampel & Kuat Luluh (MPa) & Kuat Tarik (MPa) & Elongasi (\%) & Kekerasan (HRB) \\
\hline $3-25$ & 481,34 & 802,56 & 12,40 & 95,33 \\
\hline $3-50$ & 598,63 & 862,95 & 12,60 & 97,33 \\
\hline $3-75$ & 478,58 & 792,17 & 12,75 & 96,67 \\
\hline $3-30$ & 474,44 & 769,16 & 12,30 & 98,67 \\
\hline $6-25$ & 470,71 & 733,15 & 9,50 & 97,67 \\
\hline $6-50$ & 537,07 & 808,13 & 13,75 & 98,33 \\
\hline $6-75$ & 520,70 & 784,63 & 15,00 & 93,33 \\
\hline $6-30$ & 471,65 & 783,28 & 12,55 & 95,67 \\
\hline
\end{tabular}

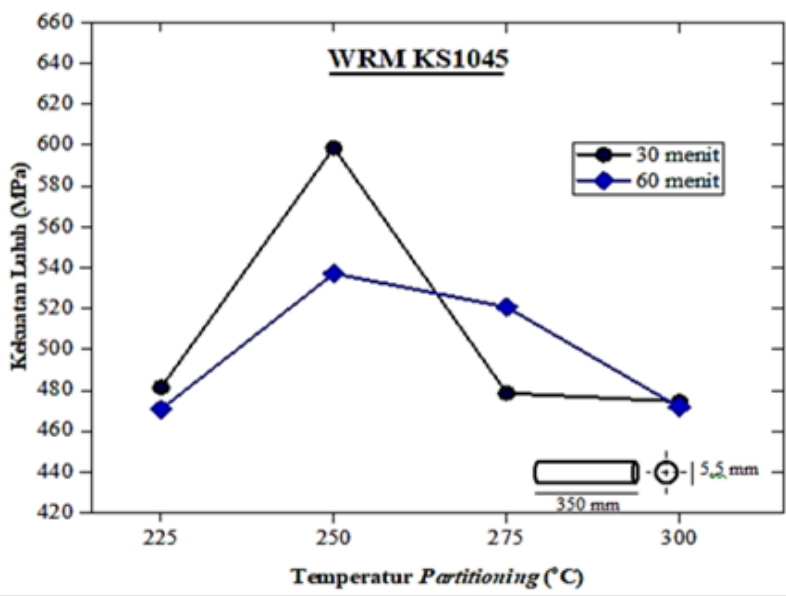

(a)

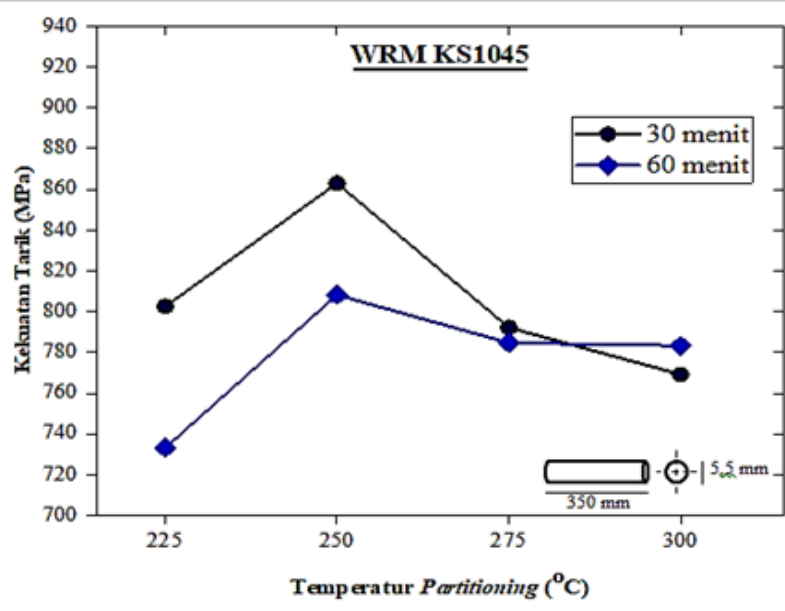

(b)

Gambar 3. Pengaruh Waktu Tahan Austenisasi dan Temperatur Partitioning terhadap (a) Kekuatan Luluh dan (b)

kekuatan tarik

Pada Gambar 3(a) menunjukan bahwa baja WRM 1045 yang telah dilakukan proses Q\&P mengalami perubahan nilai kuat luluh. Pada waktu tahan austenisasi 30 dan 60 menit, kekuatan luluh mengalami penurunan setelah temperatur partitioning $250^{\circ} \mathrm{C}$. Nilai kuat luluh tertinggi yaitu terdapat pada sampel dengan waktu tahan austenisasi 30 menit dan temperatur partitioning $250^{\circ} \mathrm{C}$ sebesar 598,63 MPa. Sedangkan nilai kuat luluh terendah terdapat pada sampel dengan waktu tahan austenisasi 60 menit dan temperatur partitioning $300^{\circ} \mathrm{C}$ dengan nilai kuat luluh sebesar $471,65 \mathrm{MPa}$. Sedang Gambar 3(b) menunjukan bahwa nilai kuat tarik sampel baja dengan waktu tahan austenisasi 30 dan 60 menit juga mengalami penurunan nilai kuat tarik saat temperatur partitioning diatas $250^{\circ} \mathrm{C}$. Nilai kuat tarik tertinggi terdapat pada sampel dengan waktu tahan austenisasi 30 menit dan temperatur partitioning $250^{\circ} \mathrm{C}$ sebesar $862,95 \mathrm{MPa}$, sedangkan nilai kuat tarik terendah terdapat pada sampel dengan waktu tahan 60 menit dan temperatur partitioning $225^{\circ} \mathrm{C}$ sebesar $733,15 \mathrm{MPa}$. Terjadinya peningkatan nilai kuat luluh dan kuat tarik pada sampel dengan waktu tahan austenisasi 30 dan 60 menit karena pada temperatur partitioning $250^{\circ} \mathrm{C}$ terjadi peningkatan jumlah fraksi martensit. Sedangkan terjadinya penurunan nilai kuat luluh dan kuat tarik pada sampel dengan temperatur partitioning diatas $250^{\circ} \mathrm{C}$ karena meningkatnya jumlah fraksi fasa RA yang menyebabkan berkurangnya jumlah karbon dalam martensit.

Penurunan nilai kuat luluh dan kuat tarik juga disebabkan oleh pengaruh ukuran butir. Pada waktu tahan austenisasi 60 menit menghasilkan nilai kuat luluh dan kuat tarik yang lebih rendah dibandingkan dengan waktu tahan austenisasi 
30 menit. Ukuran butir yang besar akan menyebabkan dislokasi lebih mudah bergerak dan menghasilkan lebih banyak RA yang terbentuk sehingga mengurangi kekuatan baja. Hal ini menunjukan bahwa baja yang dilakukan proses Q\&P pada temperatur partitioning diatas $250^{\circ} \mathrm{C}$ akan menyebabkan nilai kuat luluh dan kuat tariknya semakin menurun.

Pada Gambar 4 menunjukan bahwa elongasi baja setelah dilakukan proses Q\&P mengalami peningkatan seiring dengan temperatur partitioning yang semakin tinggi. Sampel baja WRM 1045 yang memiliki nilai elongasi tertinggi adalah sampel dengan waktu tahan austenisasi 60 menit dan temperatur partitioning $275^{\circ} \mathrm{C}$ sebesar $15 \%$, sedangkan sampel yang memiliki elongasi terendah adalah sampel dengan waktu tahan austenisasi 60 menit dan temperatur partitioning sebesar $9,5 \%$. Elongasi menurun ketika temperatur partitioning mencapai $300^{\circ} \mathrm{C}$. Elongasi yang dihasilkan pada sampel dengan waktu tahan austenisasi 60 menit lebih tinggi dibandingkan dengan waktu tahan austenisasi sebesar 30 menit. Hal ini terjadi karena semakin lama waktu tahan austenisasi, maka ukuran butir austenit akan semakin besar. Ukuran butir austenit yang semakin besar dapat memperlambat terbentuknya martensit ketika proses initial quenching dan meningkatkan terbentuknya RA [10]. Semakin tinggi temperatur partitioning maka elongasi yang dihasilkan semakin meningkat. Namun mengalami penurunan elongasi ketika temperatur partitioning sebesar $300^{\circ} \mathrm{C}$. Hal ini dapat terjadi karena, bertambahnya fraksi fasa martensit dan berkurangnya fraksi fasa RA ketika temperatur partitioning $300^{\circ} \mathrm{C}$. Semakin tinggi temperatur partitioning, maka atom-atom karbon semakin mudah untuk berdifusi dari martensit menuju $R A$ dan mengakibatkan fasa RA tidak stabil. Ketika proses final quenching fasa RA yang tidak stabil tersebut dapat bertransformasi kembali menjadi martensit baru yang sifatnya lebih keras dibandingkan dengan martensit yang terbentuk saat proses initial quenching.

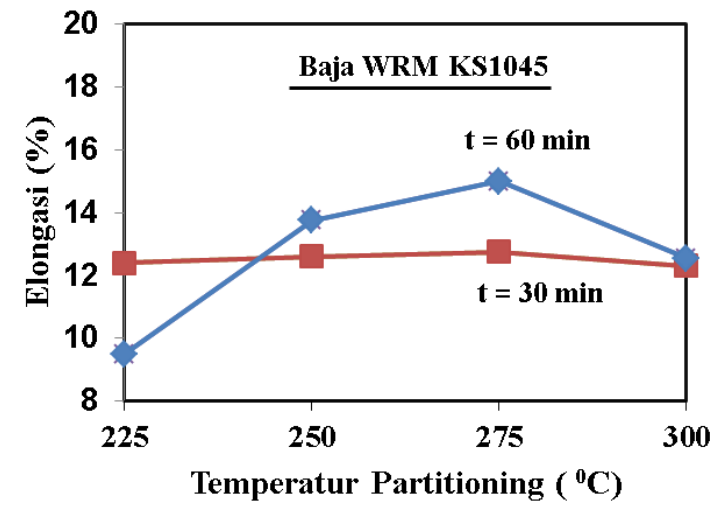

Gambar 4. Pengaruh Waktu Tahan Austenisasi dan Temperatur Partitioning terhadap Elongasi

Pada Gambar 5 menunjukan bahwa nilai kekerasan baja meningkat setelah dilakukan proses Q\&P. Nilai kekerasan tertinggi yaitu terdapat pada sampel dengan waktu tahan 30 menit dan temperatur partitioning $300^{\circ} \mathrm{C}$ sebesar 98,67 HRB. Sedangkan nilai kekerasan terendah terdapat pada sampel dengan waktu tahan austenisasi 60 menit dan temperatur partitioning $275^{\circ} \mathrm{C}$ sebesar 93,33 HRB. Peningkatan nilai kekerasan pada sampel disebabkan karena terbentuknya fasa martensit pada baja yang telah dilakukan proses Q\&P dan dipengaruhi adanya fasa fresh martensite yang dapat terbentuk akibat adanya fasa RA yang tidak stabil sehingga ketika proses final quenching, RA tersebut bertransformasi menjadi martensit baru (fresh martensite) yang sifatnya lebih keras dan getas dibandingkan dengan martensit yang terbentuk saat proses initial quenching. Namun kekerasan baja mengalami penurunan ketika temperatur partitioning $275^{\circ} \mathrm{C}$ yaitu terdapat pada. Hal ini dapat disebabkan karena bertambahnya jumlah fasa RA pada sampel 375 dan sampel 6-75 yang menyebabkan karbon pada fasa martensit berpindah sebagian menuju RA. Sehingga elongasi 
Ali Alhamidi, dkk./Jurnal Rekayasa Mesin p-ISSN: 1411-6863, e-ISSN: 2540-7678

Vol.15|No.2|118-125|Agustus|2020

yang dihasilkan pada sampel waktu tahan austenisasi 60 menit dengan temperatur partitioning $275^{\circ} \mathrm{C}$ lebih besar dan menyebabkan nilai kekerasan pada sampel tersebut juga paling rendah.

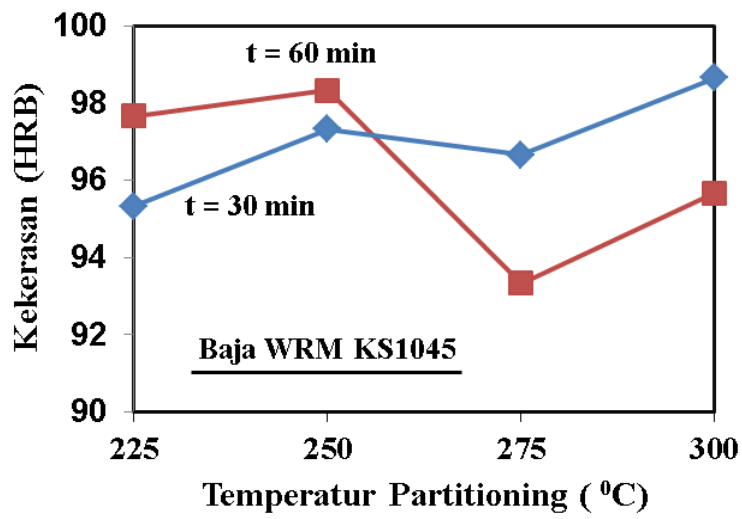

Gambar 5. Pengaruh Waktu Tahan Austenisasi dan Temperatur Partitioning terhadap Kekerasan

Gambar 6, menunjukan hasil foto mikro dengan microskop optik dengan dengan a) kondisi awal sebelum perlakuan, b) waktu tahan 30 menit dengan TP $275^{\circ} \mathrm{C}$ dan (c) waktu tahan 60 menit dengan TP $275^{\circ} \mathrm{C}$ (Perbesaran 500x). Dari pengamatan menunjukan bahwa sampel yang belum dilakukan proses Q\&P menunjukan hadirnya fasa perlit dan ferit. Sedangkan pada sampel yang telah dilakukan proses Q\&P terdapat fasa martensit dan RA yang jumlahnya dapat dilihat pada Tabel 3.

Tabel 3. Hasil Analisa Metalografi Kuantitatif

\begin{tabular}{|c|c|c|c|c|}
\hline t $\gamma$ (menit) & $\mathrm{Tp}\left({ }^{\circ} \mathrm{C}\right)$ & Fraksi Martensit (\%) & Fraksi $R A(\%)$ & Ukuran Butir $(\mu \mathrm{m})$ \\
\hline 30 & 225 & 78,38 & 21,62 & 18,95 \\
\hline 30 & 250 & 84,32 & 15,68 & 30,96 \\
\hline 30 & 275 & 73,11 & 26,89 & 33,65 \\
\hline 30 & 300 & 74,46 & 25,54 & 39,95 \\
\hline 60 & 225 & 73,61 & 26,39 & 20,80 \\
\hline 60 & 250 & 77,05 & 22,95 & 28,25 \\
\hline 60 & 275 & 68,81 & 31,19 & 36,51 \\
\hline 60 & 300 & 79,61 & 20,39 & 40,12 \\
\hline
\end{tabular}

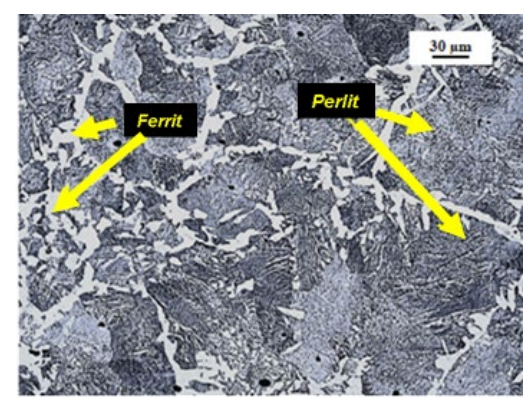

(a)

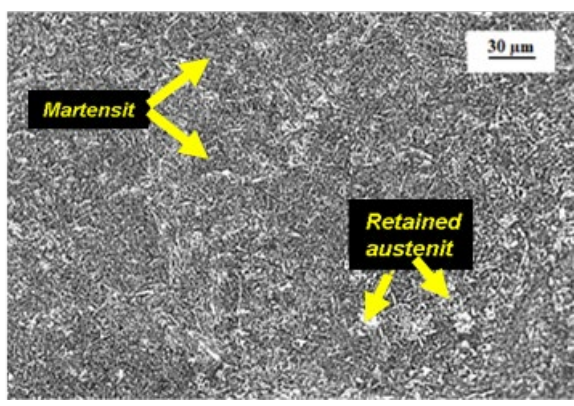

(b)

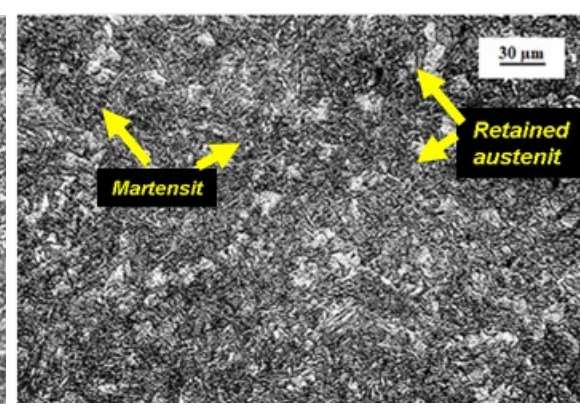

(c)

Gambar 6. Hasil foto mikro baja Baja WRM 1045 dengan a) kondisi awal, b). waktu tahan 30 menit dengan TP $275^{\circ} \mathrm{C}$ dan (c) waktu tahan 60 menit dengan TP $275^{\circ} \mathrm{C}$ (Perbesaran 500x)

\section{Kesimpulan}

Berdasarkan hasil dan pembahasan, maka dapat disimpulkan bahwa semakin lama waktu tahan austenisasi dan temperatur partitioning maka nilai kuat luluh, kuat tarik, elongasi, dan nilai kekerasan akan semakin menurun. Nilai 
Ali Alhamidi, dkk./Jurnal Rekayasa Mesin p-ISSN: 1411-6863, e-ISSN: 2540-7678 Vol.15|No.2|118-125|Agustus|2020

kuat luluh dan kuat tarik tertinggi terdapat pada sampel dengan waktu tahan austenisasi 30 menit dan temperatur partitioning $250^{\circ} \mathrm{C}$ yaitu sebesar 598,63 MPa dan 862,95 MPa, sedangkan elongasi tertinggi terdapat pada sampel dengan waktu tahan austenisasi 60 menit dan temperatur partitioning $275^{\circ} \mathrm{C}$ yaitu sebesar $15 \%$. Nilai kekerasan tertinggi terdapat pada sampel dengan waktu tahan austenisasi 30 menit dan temperatur partitioning $300^{\circ} \mathrm{C}$ yaitu sebesar 98,67 HRB. Selain itu semakin tinggi waktu tahan austenisasi dan temperatur partitioning akan menyebabkan jumlah fraksi fasa martensit meningkat dan fraksi fasa RA menurun, sedangkan ukuran butir akan semakin meningkat. Jumlah fraksi fasa martensit tertinggi terdapat pada sampel dengan waktu tahan austenisasi 30 menit dan temperatur partitioning $250^{\circ} \mathrm{C}$ yaitu sebesar $84,32 \%$. Jumlah fraksi fasa RA tertinggi terdapat pada sampel dengan waktu tahan austenisasi 60 menit dan temperatur partitioning $275^{\circ} \mathrm{C}$ yaitu sebesar 31,19\%. Sedangkan ukuran butir terbesar tedapat pada sampel dengan waktu tahan austenisasi 60 menit dan temperatur partitioning $300^{\circ} \mathrm{C}$ sebesar $40,12 \mu \mathrm{m}$.

\section{Daftar Pustaka}

[1] Yamagata, H. The Science and Technology of Materials in Automotive Engines. 1st Edition. United Kingdom: Woodhead publishing; August 2005. p. 105.

[2] Fonstein, N. Dual-Phase Steels Design, Metallurgy, Processing and Applications. Automotive. Steels. United Kingdom: Woodhead publishing; 2017, p. 169.

[3] ASM Handbook. In Properties And Selection: Irons, Steels, And High Performance Alloys. ASM International Handbook Committee; vol.1. 1990. p. 677

[4] ASM Handbook. Heat Treating. ASM International Handbook Committee; vol. 4. 1991.

[5] Baldwin, W. Metallography and Microstructures. ASM International Handbook Committee. 2004.

[6] Speer, J., DK, Matlock., BC, Cooman D., JG, Schroth. Carbon partitioning into austenite after martensite transformation. Acta materialia. 2003 May; 51(9): p. 2611.

[7] Santofimia, M.J., J, Sietsma., L, Zhao. Microstructural Evolution of a Low-Carbon Steel during Application of Quenching and Partitioning Heat Treatments after Partial Austenitization. Metallurgical and Materials Transactions A. 2009 November; 40A: p. 54

[8] Tariq, F., RA, Baloch. One-Step Quenching and Partitioning Heat Treatment of Medium Carbon Low Alloy Steel. Journal of Materials Engineering and Performance. 2014 February; 23(5): p. 1.

[9] Seo, E.J., C, Lawrence., Y,Estrin., BC, Cooman D. Microstructure-Mechanical Properties Relationships For Quenching and Partitioning (Q\&P) Processed Steel. Acta Materialia. 2016 July; 113: p. 138.

[10] Seo, E.J., C, Lawrence., BC, Cooman D. Application of Quenching and Partitioning Processing to Medium Mn Steel. Metallurgical and Materials Transactions A. 2015 January; 46(1): p. 1

[11] Ghazvinloo, H.R., A. Honarbakhsh-R., E, Borhani. Morphological Characteristics Of RA In 0.362C- 1.38Si-1. 24Mn Steel Processed By One-Step Quenching And Partitioning. Metallurgist. 2016 December; 60: p. 758.

[12] Zhang, J., H, Ding., RDK, Misra. Enhanced Strain Hardening And Microstructural Characterization In A Low Carbon Quenching And Partitioning Steel With Partial Austenization. Materials Science \& Engineering A. 2015; 636: p. 53

[13] Sains, K., W, Wijanarko. Studi Eksperimental Pengaruh Variasi Temperatur dan Waktu Penahanan Partitioning pada Proses Quenching-Partitioning Baja JIS S45C Di bawah Temperatur Martensite Start. Jurnal Teknik ITS. 2017; 6(1): p. 191. 
[14] Wijanarko, W., W, Berata, Sutikno., I, Sidharta. Experimental Study Of The Influence Of Quenching And Partitioning Temperature Variation On Retained austenite Fraction In AISI 4140 Steel. ARPN Journal of Engineering and Applied Sciences. 2016 January; 11 (2): p. 926.

[15] Clarke, A.J., MK, Miller., JG, Speer., RE, Hackenberg. Carbon Partitioning To Austenite From Martensite or Bainite During the Quench And Partition (Q\&P) Process: A Critical Assessment. Acta Materialia. 2008 January; 56(1): p. 20. 